revista ANTHROPOLÓGICAS

Ano 23, 30(2): 316-326, 2019

\title{
ENSAIO BIBLIOGRÁFICO
}

\section{Diários de Antropologia Griô: etnografia e literatura na obra de Zora Hurston}

Messias Basques $^{a}$

HURSTON, Zora Neale. 2018. Barracoon: the story of the last 'Black Cargo'. Editado por Deborah Plant. New York: Amistad.

"Todas essas palavras dos vendedores, mas nenhuma palavra dos vendidos. Os Reis e Capitães cujas palavras moveram navios. Mas nenhuma palavra de suas cargas" (Hurston 2008:42).

"Eu quero saber quem é você e como você se tornou um escravo; a qual parte da África você pertence, como era a sua vida como escravo, e como você tem vivido como um homem livre" (Hurston 2008:18).

Barracoon é o primeiro livro da antropóloga e escritora afro-americana Zora Neale Hurston (1891-1960), embora o manuscrito tenha permanecido inédito desde 1931, devido ao desinteresse dos editores em publicá-lo no formato original. Durante todos esses anos, as páginas de Barracoon estiveram depositadas nos arquivos da Universida-

a Doutor em Antropologia, Museu Nacional da UFRJ. Email: messias. basques@gmail.com 
de de Howard, em Washington. O título faz referência aos barracões onde eram aprisionados os negros submetidos ao tráfico ultramarino de escravos. Na língua inglesa, a palavra tem sentido semelhante ao de senzala, mas diferencia-se das habitações das colônias portuguesas por seu caráter temporário. Trata-se de um espaço que produzia a transfiguração de pessoas em mercadorias à espera de um destino incerto.

Não obstante a proibição do tráfico negreiro no início do século XIX, os barracões de Ouidah, em Daomé (atual República do Benim), continuavam abarrotados. $O$ fato foi noticiado nos jornais da pequena cidade de Mobile, no estado norte-americano de Alabama, e atraiu a atenção dos irmãos Meaher e do capitão William Foster. Em julho de 1860, o navio Clotilda cruzou o Atlântico e atracou na costa africana, de onde partiu carregado com uma centena de escravos. A bordo estava Kossola Oluale, um jovem Isha (povo de língua yorubá) de apenas 19 anos.

Sabe-se que as guerras de captura entre povos africanos preexistem à expansão europeia. Porém, o advento da escravidão e do tráfico negreiro modificaram o sentido tradicional dos conflitos interétnicos, provocando o acirramento das disputas pelo acesso aos recursos oferecidos aos reis africanos em troca de cativos. A captura e a venda de Kossola ilustram um dos capítulos dessa história, pois ocorreram no momento da ascensão do príncipe Glèlè ao trono de Daomé.

Quase cinquenta anos depois, Kossola recebeu em sua casa a antropóloga Zora Hurston, a quem confiou suas memórias e a tarefa de divulgá-las em um livro sobre a sua vida. Foram três meses de conversas, entrevistas e passeios de carro, além de ocasiões em que partilharam, em silêncio, a companhia um do outro, provando os pêssegos da estação e pedaços de presunto, com os quais Zora presenteava o amigo ao retornar de viagem, dando início a uma nova etapa da pesquisa. São as palavras do griô que permitiram o encontro de duas pessoas marcadas pelo desterro. Mas não se trata apenas de um encontro além -mar, pois também permitiu, como diria o poeta martinicano Aimé Césaire (2012), 'um retorno à terra natal'. Ele, guiado pela memória 
viva da diáspora. Ela, pelas lembranças de seus familiares e por ter crescido em Eatonville, na Flórida, onde negros libertos fundaram uma cidade afro-americana. Em sua autobiografia, Zora Hurston afirma que a jornada de Kossola a afetou de maneira incontornável e a fez refletir sobre o fato de que o seu povo os vendeu e os brancos os compraram (Hurston 2006 [1942]:132-133). O que nos permite compreender a experiência transformadora originada nessa amizade, como na definição do filósofo Giorgio Agamben: "o amigo não é um outro eu, mas uma alteridade imanente no eu, um devir outro de si” (2007:34).

A abertura do livro é de autoria de Alice Walker, uma das principais responsáveis pela redescoberta de Zora Hurston e pela republicação de suas obras nos Estados Unidos. Foi Walker quem localizou, em 1973, o cemitério onde Zora Hurston havia sido enterrada em uma vala comum e sem identificação, após o ostracismo (causado por uma falsa acusação de que teria molestado uma criança) e o isolamento que marcaram os últimos anos de sua vida. Valerie Boyd (2004), autora de uma extensa biografia de Hurston, localizou uma carta onde ela confidenciava a W.E.B. Du Bois (intelectual negro, precursor da sociologia e da psicologia norte-americanas) o temor de que os amigos morressem na miséria. Hurston perguntava a Du Bois a sua opinião a respeito da criação de um cemitério destinado a 'negros ilustres', cuja missão seria salvá-los do esquecimento na posteridade. Quis o destino que o 'Dr. Dúbio', como ela carinhosamente o chamava, tivesse um 'funeral de estado' em Acra, capital de Gana, enquanto Hurston sucumbiu à própria profecia. Foi Alice Walker quem a resgatou do anonimato póstumo, reformando o seu túmulo e instalando no local uma lápide onde se pode ler: "Zora Neale Hurston: um gênio do Sul. Novelista, folclorista e antropóloga".

Se Barracoon revela aos leitores as feridas abertas pela escravidão e pela diáspora, Alice Walker sugere que as palavras de Hurston e Kossola enunciam os elementos necessários ao processo de cura. A seu ver, trata-se de uma "maestrapiece" (2018:13). O livro contém 12 capítulos, 
dos quais sete possuem títulos que registram os principais momentos da vida de Kossola. No 'Apêndice', encontram-se outras seis histórias, que remetem às tradições e aos costumes dos Isha de Bantè. Coube a Deborah Plant a edição e a revisão de todas as fontes e referências do manuscrito original. Plant também assina a 'Introdução' e o 'Posfácio', nos quais descreve o contexto em que se deu a pesquisa de campo de Zora Hurston e as relações ambivalentes com a 'madrinha', Charlotte Osgood Mason (mulher branca da elite nova-iorquina e financiadora de artistas e escritores negros do Harlem), e com Franz Boas, seu orientador no Barnard College da Universidade de Colúmbia.

No dia 14 de dezembro de 1927, Hurston viajou para a cidade de Mobile, onde daria início a uma série de entrevistas com Kossola Oluale, cujo nome norte-americano é Cudjo Lewis. À época, ele era um dos poucos sobreviventes, senão o único, do último navio negreiro a cruzar o Atlântico com destino aos Estados Unidos. Com uma 'bolsa' de 1.400 dólares, concedida pela Associação para o Estudo da Vida e da História do Negro e pela Sociedade Americana de Folclore (SAF), Zora viajava em um Chevrolet e levou em sua bagagem duas câmeras, para o registro de fotografias e vídeos, e uma pistola. A precaução era justificada, pois, como se sabe, o racismo não se resumia às leis segregacionistas, instauradas em 1876, e motivava incontáveis agressões e assassinatos de pessoas negras, sobretudo nos estados do Sul.

No 'Prefácio', de 17 de abril de 1931, Zora nos diz que esta é a história de vida de Kossola, narrada por ele mesmo. Na 'Introdução', descobrimos que o seu 'jeito barnadesco', fruto dos anos de formação acadêmica, inibia os interlocutores da jovem antropóloga, ainda que ela estivesse iniciando a carreira em um ambiente familiar, cuja oralidade revelava um "jeito negro de dizer" (cf. Hurston 2006:226). Algo semelhante ao que propôs a antropóloga Lélia Gonzalez, ao se referir ao "pretuguês" (1984:235) como língua materna no Brasil.

Zora Hurston não ocupa a posição de 'redatora ausente' ou de 'escritora fantasma'. Sua presença no texto se evidencia na apresentação de questões que servem de contraponto à narrativa, como se 
ambos estivessem a conversar diante de um público de leitores. Por essa razão, as palavras de Kossola aparecem inscritas em uma oratura própria e não foram submetidas às convenções da linguagem acadêmica ou erudita. $\mathrm{O}$ que favorece a expressão da escrita de um corpo, de uma condição e de uma experiência negra, como na 'escrevivência' de Conceição Evaristo (2008). Por outro lado, a defesa da oratura representaria um obstáculo para a publicação do livro, pois ainda que os editores tenham demonstrado interesse pela história, alegavam que seria inviável publicá-la enquanto estivesse escrita em um 'dialeto'. A mesma reticência foi demonstrada por Franz Boas, que alguns anos mais tarde hesitaria diante do convite de Hurston para que assinasse a introdução ao livro 'Mules and Men' (1935; cf. Meisenhelder 2007).

No primeiro capítulo de Barracoon, Kossola é questionado sobre o motivo de se apresentar como um homem cristão. Com o humor habitual, explicou que o seu povo sabia da existência de Deus, mas que, por serem analfabetos, ainda não haviam lido a Bíblia e tampouco descoberto que Ele possuía um filho. Surpreso com a curiosidade demonstrada por Hurston, mostrou-se entusiasmado com a possibilidade de que pudessem ler a seu respeito em África e que um dia alguém dissesse: eu me lembro de Kossola.

Em um dado momento da conversa, quando enveredava pelas memórias do avô, Hurston o interrompeu a fim de retomar uma narrativa aparentemente inacabada. Contrariado, ele a advertiu com um provérbio: "Qual é a casa onde um rato é o Rei?" (2018:63). Não se pode falar do filho antes de falar do pai, e não se pode falar do pai antes de falar do avô. Em seguida, Kossola recorda que os Isha possuíam cativos, mas que o avô e os chefes não aceitavam vendê-los aos europeus, nem sequer nos casos de indisciplina ou de faltas graves por eles cometidas.

O segundo capítulo retrata o cotidiano de uma comunidade Isha e as regras impostas à caça de leopardos, cuja infração poderia resultar na morte do caçador em uma festa dedicada à celebração da realeza. No terceiro, somos apresentados aos rituais funerários e às cenas de 
sepultamento de familiares no interior das casas, que constituíam os primeiros momentos de um longo e penoso período de luto. O quarto capítulo é dedicado à sua família e às histórias que sua mãe contava sobre o tempo em que os animais falavam e viviam como humanos. A iniciação nas tradições isha o levou a aprender algumas das técnicas de caça e de guerra, mas foi bruscamente interrompida por um ataque perpetrado pelo Rei de Daomé.

O capítulo cinco aborda o episódio que culminou na sua captura e aprisionamento nos barracões de Ouidah. O Rei isha teria se recusado a atender as ordens de Daomé, que exigia a metade das plantações de milho daquele ano. A traição de um homem isha, que revelou os segredos dos portões que protegiam a comunidade, permitiu que fossem atacados de surpresa, no meio da noite. As tropas avançaram com armas de fogo, enquanto as amazonas capturavam jovens e crianças e recolhiam as cabeças dos mortos, inclusive a do Rei, como troféus de guerra.

No sexto capítulo, Kossola narra a longa jornada até Abomei, antiga capital de Daomé. Foi nos barracões que ele viu, pela primeira vez em sua vida, os homens brancos. O comércio era precedido por uma inspeção minuciosa, mas muitas vezes os cativos eram vendidos em lotes e levados aos navios em grupos que conservavam parte dos vínculos de parentesco e de amizade anteriores à escravidão. Kossola descreve o sentimento de vergonha por ter sido obrigado a viajar nu, e que os olhares dos americanos que os viram despidos fizeram-no compreender o significado da palavra "selvagem" (2018:111).

A tripulação do Clotilda oferecia pequenas porções de comida aos escravos, suficientes apenas para que não morressem de inanição, e água com vinagre, para evitar que desenvolvessem escorbuto. Kossola e os outros Isha jamais haviam navegado em alto mar. Cercados por uma imensidão de água, viram-se apavorados com o som das ondas que se chocavam contra o navio, cujas madeiras rangiam como se estivessem prestes a se partir. No desembarque em terras norte-americanas, o navio foi queimado e naufragou, para que não restassem pis- 
tas do contrabando de escravos. Atacados por nuvens de mosquitos, foram obrigados a se esconder e a caminhar através de pântanos, antes de chegar ao destino final nas plantações de Alabama.

Este é o tema do sétimo capítulo. O que causava tristeza, choro e desespero não era o trabalho exaustivo a que estavam submetidos, mas o fato de terem sido arrancados de suas casas e submetidos à escravidão. Durante cinco anos e meio, Kossola trabalhou em diversas plantações nas margens dos rios Alabama e Tennessee, até o início da Guerra de Secessão. Ele conta que não sabiam o que estava acontecendo e que ouviram alguém dizer que as tropas do Norte libertariam os escravos do Sul. Nos dias seguintes, avistaram soldados que disseram que estavam livres. Kossola e os outros perguntaram aonde deveriam ir e os soldados teriam respondido: 'não sabemos'.

No capítulo oito, a comemoração ao som de tambores e danças africanas cede lugar à descoberta de que não teriam terras para construir as suas próprias casas nem recursos para retornar à África. Foram necessários anos de trabalho, em liberdade, para que pudessem comprar as terras onde fundaram a comunidade de Africatown. O capítulo nove é dedicado à sua esposa e aos filhos, aos quais Kossola e Abila (Celia Lewis) deram nomes isha e norte-americanos. Os brancos que viviam na região os tratavam como selvagens, o que provocou conflitos e agressões contra sua família. A comunidade negra se viu obrigada a construir uma escola, já que as crianças e os jovens não podiam frequentar as instituições reservadas aos brancos. A sua família e amigos tornaram-se membros de uma Igreja Batista, onde Kossola atuava como diácono, mas ele conta que ainda podia ouvir os tambores e as músicas africanas ecoando em seus ouvidos.

Um após o outro os seus filhos faleceram. O primeiro, assassinado por um policial branco, com um tiro no pescoço. Outro foi atropelado e decapitado na linha de trem que cruzava a cidade. No capítulo 10, Kossola diz que aprendeu sobre as leis americanas ao também ser atropelado na mesma ferrovia. Com o apoio de um advogado, ele processou a companhia ferroviária e obteve o direito a uma indenização, 
cujo pagamento jamais fora realizado. No capítulo 11 , ao aceitar o pedido de Hurston para que posasse para uma sessão de fotografias, vemos um belo senhor negro, de terno e pés descalços. Segundo ele, os Isha não tinham o hábito de calçar sapatos e sandálias.

O tema do último capítulo é a solidão de sua velhice, após a morte da esposa e de todos os filhos, restando apenas a companhia de uma nora e de duas netas que herdaram as suas terras. Em outubro de 1928, em sua última visita, Hurston se despediu de Kossola e retornou à Nova Iorque. No 'Posfácio', Debora Plant recupera a correspondência da antropóloga e revela que ela o descrevia como "um senhor velho e poético" que sabia contar boas histórias (2018:192).

Antes de Barracoon, Zora Hurston já havia escrito a respeito de Kossola Oluale para o Journal of Negro History, em 1927. A maior parte do texto, no entanto, se baseava no livro de Emma Langdon Roche, publicado em 1914, no qual a autora, da elite escravagista de Alabama, reconstitui a história do navio Clotilda. Nenhuma acusação de plágio foi encaminhada ao jornal, mas, há de se convir, que embora Zora Hurston tenha utilizado os dados históricos e estatísticos sem as devidas regras de citação, o eventual dano autoral em nada equivale à apropriação de corpos negros submetidos à escravidão nas fazendas de Roche e de sua família. É provável que Hurston tenha se sentido pressionada a publicar um artigo no jornal, editado pela SAF, como contrapartida ao financiamento que ela havia recebido, em um momento em que a pesquisa e o manuscrito ainda se encontravam em estado incipiente. $\mathrm{O}$ caráter ambivalente das relações entre escritores e artistas negros e os seus 'patronos' e 'madrinhas' brancos, uma das diversas faces do problema racial nos Estados Unidos, levou Hurston a escrever um artigo sobre o tema, com um título contundente: 'O sistema do negro pet' (1943).

Em Barracoon (1931), Mules and Men (1935) e Tell my Horse: Voodoo and Life in Haiti and Jamaica (1938), obras escritas durante a formação em antropologia e baseadas em pesquisas de campo em comunidades negras e nas ilhas do Caribe, Zora seguiu a orientação que Franz Boas 
transmitia aos alunos: cada cultura deve ser compreendida em seus próprios termos. Porém, como diria Audre Lorde: "As ferramentas do mestre nunca desmontarão a sua própria casa” (1984:112). Em outras palavras, e seguindo as críticas do antropólogo sul-africano Archie Mafeje (2008), pode-se imaginar a improbabilidade de que uma antropologia euro-americana seja capaz de promover a superação dos estereótipos criados por ela mesma a partir de conceitos como os de alteridade e relativismo cultural. Vale lembrar que os conceitos de selvagem, primitivo, tribo, etc., que foram ostensivamente atribuídos aos negros em estudos que os tomaram como objetos de observadores brancos, ainda hoje fundamentam um conjunto de imagens atribuídas à África, como se fossem expressões factuais e fidedignas das sociedades africanas.

Nas obras de Zora Hurston, os 'grandes divisores' cedem lugar a um processo de correspondência, polifonia e autoconhecimento, para além da convencional (o)posição Nós x Eles. Como a renomada bailarina afro-americana Katherine Dunham (1909-2006), que produziu obras de antropologia e logo percebeu que o palco dos teatros permitia uma relação mais fecunda e simétrica com as danças de origem africana, Hurston desenvolveu uma forma de escrita que, ainda na década de 1930, apresenta uma solução original às críticas que os pósmodernistas enunciariam somente cinquenta anos mais tarde.

Barracoon narra a história de Kossola reconhecendo-o como autor e não como um nativo ou informante. E mesmo em suas obras de literatura, como o clássico 'Seus olhos viam Deus' (1937), Hurston conserva a oratura característica da fala e das vidas de seus personagens. Ao som das palavras do griô, pode-se presumir o cuidado e a engenhosidade que serão necessários à tradução de Barracoon ao português. Dificuldade esta que, de certo modo, assemelha-se àquela imposta aos tradutores da obra de Guimarães Rosa para outros idiomas.

No artigo 'O que os editores brancos não publicarão' (1947), Hurston defendia a necessidade de uma literatura que revelasse o negro em sua profundidade, para além das representações que se ba- 
seiam em uma estereotipia pseudocientífica, rasa e preconceituosa ( $c f$. Basques 2019). Uma literatura que estivesse à altura da sabedoria e da riqueza da vida cotidiana. Em sua opinião, assim como a escrita acadêmica e a literatura de massa, os "Museus de História (Não-)Natural" (1950:55) teriam contribuído para a formação de uma compreensão superficial das vidas de povos indígenas e negros, pois a representação do 'Outro' nesses espaços se resumiria à exposição de objetos retirados de seus contextos e a bonecos de cera e palha, incapazes de falar por si mesmos.

Beatriz Perrone-Moisés comenta que "a tradição de desconsiderar as traduções propostas pelos índios na língua do antropólogo é antiga e parece obviamente mais um empecilho do que uma garantia de conhecimento" (2015:20). Se o 'português dos índios' costuma ser submetido a convenções acadêmicas e a processos de tradução imersos em dilemas epistemológicos, o 'jeito negro de dizer' que percorre a obra de Zora Hurston revela, por sua vez, não apenas o interesse pelo que se costuma chamar de 'folclore', mas justamente o empenho da autora em estabelecer 'pactos etnográficos' com os seus interlocutores. Pactos que dependem de uma colaboração discursiva e de um 'duplo eu', surgido da relação entre autores, a fim de que o texto supere a "relação hierárquica inerente à situação etnográfica e à produção escrita que dela decorre" (Albert 2015:536).

Zora Hurston não é uma autora cuja obra se resume ao período de nascimento e de institucionalização da Antropologia nos Estados Unidos. Tampouco é suficiente dizer que foi aluna de Franz Boas ou que sua trajetória deve ser compreendida pelo trânsito incomum e bem-sucedido entre a etnografia e a ficção. Trata-se de uma antropóloga que, em diversos aspectos, esteve adiante de seu tempo e que nos permite repensar a própria história da disciplina, os seus métodos e formas de escrita. A cumplicidade e o aprendizado com autores como Kossola Oluale fizeram de Zora Hurston uma das maiores escritoras do século XX. Uma antropóloga griô, cuja contribuição às ciências sociais ainda não foi devidamente reconhecida. 


\section{Referências:}

AGAMBEN, Giorgio. 2007. L'Amitié. Paris: Payot.

ALBERT, Bruce. [2010] 2015. "Postscriptum - Quando eu é um outro (e viceversa)". In KOPENAWA, D. \& ALBERT, B. (eds.): A queda do céu: palavras de um xamã yanomami, pp. 512-549. São Paulo: Companhia das Letras.

BAQUES, Messias. 2019. "Zora Hurston e as luzes negras das Ciências Sociais. Ayé". Revista de Antropologia, 1(1):102-105.

CÉSAIRE, Aimé. [1947] 2012. Diário de um retorno ao país natal. São Paulo: EdUSP.

BOYD, Valerie. 2004. Wrapped in rainbows: the life of Zora Neale Hurston. New York: Lisa Drew Books/Scribner.

EVARISTO, Conceição. 2008. "Escrevivências da afro-brasilidade: história e memória”. Releitura, 23:1-17.

GONZALEZ, Lélia. 1984. "Racismo e sexismo na cultura brasileira". Ciências Sociais Hoje, 2:223-244.

HURSTON, Zora Neale. 1927. "Cudjo's Own Story of the Last African Slaver." Journal of Negro History, 12:648-63. [1935] 1990. Mules and Men. New York: HarperPerennial. . [1938] 1990. Tell My Horse: Voodoo and Life in Haiti and Jamaica. New York: Harper Perennial. . [1942] 1996. Dust Tracks on a Road. New York: HarperPerennial. .1943. "The 'Pet Negro' System." American Mercury, 56:593-600. . 1950. "What White Publishers Won't Print." In NAPIER, W. (ed.): African American Literary Theory: A Reader, pp.54-57. New York: NYU Press. . [1937] 2002. Seus olhos viam Deus. Rio de Janeiro: Record. 2018. "Barracoon: the story of the last 'Black Cargo'”. New York: Amistad. (Ebook Kindle)

LORDE, Audre. 1984. Sister Outsider: Essays and Speeches. New York: Crossing Press Feminist Series.

MAFEJE, Archie. 2008. "A commentary on anthropology and Africa". Codesria Bulletin, 3-4:88-94.

MEISENHELDER, Susan. 2007. "Conflict and Resistance in Zora Neale Hurston's Mules and Men”. In BLOOM, H. (ed.): Zora Neale Hurston - Bloom's Modern Critical Views, pp.105-130. New York: Bloom's Literary Criticism.

PERRONE-MOISÉS, Beatriz. 2015. Festa e Guerra. Tese de Livre-Docência. São Paulo: Universidade de São Paulo. 